\title{
Evidências sobre curva ambiental de Kuznets e convergência das emissões
}

\author{
Ednilson Sebastião de Ávila \\ Doutorando - Escola Superior de Agricultura "Luiz de Queiroz" (ESALQ) \\ Endereço: Av. Pádua Dias, 11 - Piracicaba/SP - São Paulo - Brasil \\ CEP: 13418-900 - E-mail: ednilsonsavila@gmail.com
}

Eliezer Martins Diniz

Professor - Faculdade de Economia, Administração e Contabilidade de Ribeirão Preto (FEA-RP)

Endereço: Av. Bandeirantes, 3900 - Ribeirão Preto/SP - São Paulo - Brasil

CEP: 14040-905 - E-mail: elmdiniz@usp.br

Recebido em 16 de maio de 2013. Aceito em 11 de setembro de 2014.

\section{Resumo}

Recentemente, diversos pesquisadores se dedicaram a estudar a relação existente entre crescimento econômico e poluição. Desses estudos surgiram dois enfoques distintos: a Curva Ambiental de Kuznets (CAK) e a convergência das emissões. Neste contexto, Brock e Taylor (2010) desenvolveram um modelo que faz uma ligação entre estas duas metodologias, à medida que a convergência de emissões implica a CAK. O objetivo deste artigo é estimar a CAK (de um modo tradicional) e o modelo de Brock e Taylor (2010) com o intuito de verificar se os resultados se reforçam mutuamente. As estimações da curva foram sensíveis ao modelo escolhido. A estimação do modelo apontou evidências de convergência condicional das emissões per capita e da CAK.

\section{Palavras-Chave}

Curva Ambiental de Kuznets. Convergência das emissões. Crescimento econômico.

\begin{abstract}
Recently many researchers started to study the relationship between economic growth and pollution. Two distinct approaches followed from these studies: the Environmental Kuznets Curve (EKC) and the convergence of emissions. In this context, Brock and Taylor (2010) built a model that makes a bridge between both methodologies, as convergence of emissions implies the EKC. The purpose of this paper is to estimate the EKC (in a traditional way) and the model proposed by Brock and Taylor (2010) in order to verify if the results reinforce each other. The estimates of the curve were sensitive to the model chosen. The estimates of the model pointed to evidence of conditional convergence of per capita emissions and of the EKC.
\end{abstract}

\section{Keywords}

Environmental Kuznets Curve. Convergence of emissions. Economic growth.

\section{JEL Classification}

C33. Q43. Q51

- Os autores agradecem os comentários de um parecerista anônimo. 


\section{Introdução}

A energia ocupa um papel de destaque no desenvolvimento econômico. A partir da Revolução Industrial, as inovações tecnológicas favoreceram o uso crescente de combustíveis fósseis. A consequência direta desse uso é o aumento da concentração de $\mathrm{CO}_{2}$ na atmosfera (ultrapassando 400 ppm no Observatório de Mauna Loa, em 2013). Assim, atribui-se este resultado ao crescimento econômico, visto como o principal responsável pela poluição gerada que provocou danos ao meio ambiente. Discussões a respeito dos conflitos entre crescimento econômico e meio ambiente se iniciaram na década de 1970, quando se defendeu que o meio ambiente, por causa da finitude de recursos naturais, cria limites ao crescimento econômico (Meadows et al., 1972).

Porém, com o avanço dos estudos referentes ao crescimento econômico e meio ambiente, uma nova visão surgiu. Por essa ótica, seria possível conciliar a riqueza de um país com um ambiente sustentável. Neste contexto, duas metodologias podem ser destacadas: a Curva Ambiental de Kuznets, desenvolvida por Grossman e Krueger (1991), Shafik e Bandyopadhyay (1992) e Panayotou (1993); e a convergência das emissões, proposta por List (1999).

A Curva Ambiental de Kuznets (CAK deste ponto em diante) postula uma relação entre emissões e renda no formato de $U$ invertido. Em níveis iniciais do crescimento econômico, renda e emissões guardam uma relação direta. Porém, à medida que a renda cresce e chega a um determinado nível, as emissões tendem a apresentar trajetória descendente. Isto ocorre porque, a níveis maiores de renda, as pessoas estão dispostas a buscar crescimento associado a um meio ambiente menos degradado. De acordo com Grossman e Krueger (1995), é possível explicar o formato da CAK com base em três efeitos distintos: efeito escala, quando um aumento da renda está associado a um aumento das emissões de poluentes para uma dada composição do produto e uma dada tecnologia; efeito composição, quando uma mudança da composição do produto associado a um aumento da renda leva a uma alteração do peso dos produtos menos poluentes no produto total, conduzindo a uma redução das emissões quando o peso dos produtos menos poluentes aumenta; efeito técnica, quando a adoção de tecnologias menos poluentes associada a um aumento da renda leva a uma redução das emissões. Olhando 
para a CAK, a relação direta entre renda e emissões é explicada pela predominância do efeito escala em relação aos demais. Esta relação direta ocorre nas fases iniciais do crescimento de um país. A relação inversa entre renda e emissões é explicada pela predominância dos efeitos composição e técnica sobre o efeito escala. Neste último caso, provavelmente o efeito técnica é o mais importante. Esta relação inversa ocorre no caso de países mais avançados. Segundo Grossman e Krueger (1995), o nível de renda em que as emissões atingem o máximo é conhecido na literatura como turning point (que pode ser traduzido de forma livre como pico ou ponto de inflexão). $\mathrm{O}$ ponto de inflexão pode ocorrer em um nível de renda per capita factível de ser obtido no futuro próximo. Nesse caso, a diminuição das emissões ocorreria de uma forma natural, sem a necessidade de uma intervenção da autoridade ambiental e a introdução de ineficiências dela decorrentes. Caso contrário, pode-se forçar a ocorrência do ponto de inflexão por meio de politicas ambientais apropriadas, conforme sugerido em Dasgupta et al. (2002). Por exemplo, a adoção de tecnologias menos poluentes pode ser o resultado de políticas ambientais que introduzam os incentivos corretos para a adoção de tecnologias mais limpas.

Os impactos sobre o meio ambiente associados ao crescimento econômico produziram uma série de estudos empíricos. Graças a uma maior disponibilidade de bancos de dados, a CAK passou a ser estimada para diversos tipos de poluentes. Evidências empíricas no formato de U invertido foram obtidas por Grossman e Krueger (1991), Shafik e Bandyopadhyay (1992) e Panayotou (1993). O produto comum desses estudos é a noção de que a degradação ambiental, durante os primeiros estágios do desenvolvimento, intensifica-se e, posteriormente, reduz-se, seguindo uma curva no formato de $\mathrm{U}$ invertido. Autores como Selden e Song (1994), Auci e Becchetti (2006), Fonseca e Ribeiro (2005), Carvalho e Almeida (2010) encontraram evidências favoráveis à existência da CAK.

Porém, como ressaltam Hilton e Levinson (1998), através de um exame das evidências de uma CAK para as emissões automotivas de chumbo, temos que a melhoria ambiental que acompanha o crescimento da renda depende dos tipos de política ambiental que induzem o efeito técnica, ligados aqui ao que os autores chamam de intensidade da poluição. É necessário cautela para interpretar a CAK. Segundo De Bruyn (2000), houve uma interpretação errônea de que 
a implementação de políticas de controle de emissões só seria bemsucedida quando a renda ultrapassasse certo nível. Além do mais, conforme ressaltado em Grossman e Krueger (1995), mesmo que as emissões apresentem uma trajetória na forma de $\mathrm{U}$ invertido, isso não garante que este processo de ascensão e queda das emissões se sustente no longo prazo. Logo, o crescimento econômico sozinho pode não levar ao que é postulado nesta teoria. Assim, são necessárias políticas ambientais que, juntamente com o crescimento econômico, venham a induzir a redução da pressão ambiental.

Apesar dos resultados favoráveis, muitas críticas foram feitas à hipótese da CAK. A principal reclamação reside no uso incorreto da técnica econométrica, que pode levar a evidências enganosas. Stern (2004) argumenta que, sob o rigor de uma econometria correta, a CAK não existe. Além disso, a possível relação obtida entre as variáveis pode ser espúria (Wagner, 2008). Os resultados das estimações são sensíveis ao tipo de poluente considerado. $O$ ponto de inflexão e os próprios coeficientes também se mostram sensíveis à forma funcional e ao tipo de modelo utilizado (De Bruyn, 2000).

O estudo acerca da convergência das emissões de poluentes está inspirado no modelo de Solow (1956), em que a taxa de crescimento da renda per capita é inversamente proporcional ao nível inicial da renda per capita. Uma implicação do resultado de Solow é que os países mais pobres devem alcançar os países mais ricos ao longo do tempo (desde que os parâmetros dos países sejam semelhantes). Na nova vertente que examina a convergência das emissões de poluentes, List (1999) avalia se a convergência da renda pode ocorrer juntamente com a convergência das emissões de poluentes para regiões dos EUA no período 1929-1994. List (1999) obtém o resultado de convergência dos indicadores de qualidade ambiental das regiões dos EUA. A explicação desse resultado é que as regiões mais pobres tendem a se especializar em produtos intensivos em poluição, enquanto as regiões mais ricas tendem a se especializar em bens cuja produção utiliza uma tecnologia menos poluente.

Cientes das limitações da CAK tradicional, Brock e Taylor (2010), desenvolveram um modelo teórico baseado no modelo de Solow que mostra implicitamente a existência da CAK quando ocorre a convergência das emissões. Segundo os autores, pelo fato de a equação a ser estimada ter sido obtida diretamente da teoria, a análise é mais 
robusta e o modelo não é tão sensível aos dados quanto a análise tradicional da CAK.

Este trabalho propõe-se a fazer a estimação de dois modelos diferentes: a análise tradicional da CAK e a convergência das emissões de Brock e Taylor (2010). ${ }^{l}$ Espera-se, com isso, obter resultados sobre a existência da CAK que se complementem. Essa análise mais completa é útil porque, no modelo de Brock e Taylor, a existência da CAK é implícita, não sendo possível calcular o nível de renda associado ao ponto de inflexão. Logo, é razoável supor que os resultados da convergência das emissões e da CAK sejam consistentes entre si, utilizando-se o mesmo conjunto de países.

\section{Modelo teórico}

\subsection{Curva Ambiental de Kuznets Tradicional}

O conceito de Curva Ambiental de Kuznets surgiu no começo da década de 1990 para descrever os impactos que o desenvolvimento econômico exerce sobre os níveis de emissões de poluentes, uma vez que estes estão intimamente relacionados com a produção de um país. O crescimento econômico em um país pobre vem acompanhado por emissões em níveis crescentes associadas ao crescimento da atividade produtiva. Devido à condição de pobreza do país, é dada uma prioridade menor sobre a qualidade ambiental, o que implica menos controle e poucas políticas ambientais sobre os níveis de emissões.

A partir do momento em que a renda cresce e alcança o ponto de inflexão, a prioridade dada pelos indivíduos muda em direção a um ambiente menos degradado. Se esse efeito é forte o suficiente, ocorrerá um declínio nas emissões de poluentes, de acordo com a Figura 1.

\footnotetext{
1 Embora a estimação da equação de convergência tenha sido feita por Brock e Taylor (2010), neste trabalho será adotada uma técnica mais moderna, com o uso da metodologia de painel dinâmico. Além disso, os dados que serão utilizados neste trabalho são mais atuais do que aqueles utilizados pelos referidos autores.
} 


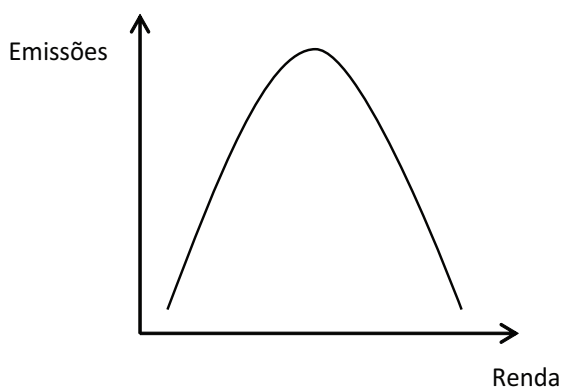

Figura 1 - Curva Ambiental de Kuznets

Fonte: elaborado pelos autores

Conforme vimos na seção anterior, existem três forças que agem por trás da CAK: efeito escala, efeito composição e efeito técnica. A hipótese teórica em que se baseia a CAK é a de que o impacto negativo do efeito escala tende a prevalecer nos estágios iniciais do crescimento econômico, sendo compensado ao longo do processo de desenvolvimento do país pelos efeitos composição e técnica, os quais tendem a reduzir os níveis das emissões.

Porém, conforme ressalta Diniz (2001), se o efeito escala predomina sobre os demais não ocorrerá a segunda fase da CAK, uma vez que um nível maior de produto sempre produz um nível maior de poluição. Segundo Diniz (2007), o efeito escala é predominante nas nações menos desenvolvidas, uma vez que o crescimento econômico é o objetivo mais desejável a priori. Já nos países desenvolvidos que estão na parte negativa da curva, os efeitos composição e técnica predominam sobre o efeito escala.

A discussão a respeito da existência da CAK se desenvolveu principalmente no plano econométrico. Esta relação, por ser empírica, fundamenta-se na seguinte expressão:

$$
E_{i t}=\alpha_{i}+\gamma t+\beta_{1} Y_{i t}+\beta_{2} Y_{i t}^{2}+\beta_{3} Y_{i t}^{3}+e_{i t}
$$

em que o subscrito $t$ se refere ao tempo, $\alpha$ é uma constante, $E_{i t}$ representa o logaritmo das emissões e $Y_{i t}$ o logaritmo da renda per capita. A curva em formato de $\mathrm{U}$ invertido surge quando $\beta_{1}>0, \beta_{2}<0$, e $\beta_{3}=0$. Neste caso o ponto de inflexão é dado por $y_{t}=\exp \left(\frac{-\beta_{1}}{2 \beta_{2}}\right)$. 
Questionamentos foram feitos de que a CAK seria um artefato empírico sem o embasamento de uma teoria econômica. A ocorrência de uma relação inversa entre poluição e renda foi apontada em diversos modelos de crescimento econômico, como, por exemplo, os relatados em Stokey (1998) e Dinda (2005). Stokey (1998) examinou os principais modelos de crescimento econômico e obteve uma condição única para o aparecimento de uma CAK e que é válida para todos os modelos. Logo, a CAK pode ocorrer em modelos de crescimento econômico microfundamentados. Segundo Stokey (1998), um método mais poluente de produção é utilizado se a capacidade produtiva estiver abaixo do ponto de inflexão. À medida que a economia cresce, o ponto de inflexão é ultrapassado e as tecnologias menos poluentes podem ser usadas. Nesse contexto, abaixo do ponto de inflexão a poluição cresce linearmente com a renda, porém, acima dele, a relação entre emissões e renda depende da elasticidade de substituição intertemporal do consumo. Se esta for menor do que um, encontra-se a relação no formato de U invertido. Através do exame de dados empíricos em Campbell e Mankiw (1989), temos que a condição de Stokey (1998) é satisfeita, de modo que pode ocorrer uma CAK e a análise empírica precisa ser feita caso a caso. Logo, a CAK pode surgir pelo próprio processo do crescimento econômico e, assim, sua existência torna-se apenas uma questão empírica.

Por outro lado, Dinda (2005) mostra a importância de políticas de controle e redução das emissões no contexto da CAK. O autor utilizou um modelo de crescimento endógeno em que uma parte do capital é utilizada para a produção de mercadorias, as quais geram poluição. Porém, outra parte do capital é usada para práticas mitigadoras no custo da poluição. Desta forma, a mudança de uma alocação insuficiente de capital para uma alocação suficiente do capital destinado à mitigação é a base para a relação em que se sustenta a CAK no modelo apresentado.

\subsection{Modelo de convergência das emissões}

Brock e Taylor (2010) desenvolveram um modelo para emissões de poluentes, intimamente ligado ao modelo de Solow. No modelo proposto, o progresso tecnológico sobre a produção de bens e redução das emissões é exógeno, o que leva a um crescimento contínuo da 
economia e também a uma melhoria na qualidade ambiental. Além disso, tanto a poupança quanto as práticas de mitigação escolhidas são, também, determinadas exogenamente. ${ }^{2}$ Desta forma têm-se as seguintes relações:

$$
Y=F(K, B L)
$$

$$
\dot{L}=n L, \dot{B}=g_{B} B, \dot{K}=s Y-\delta K
$$

O produto $Y$ possui uma função de produção estritamente côncava, com retornos constantes de escala, e utiliza os insumos trabalho efetivo e capital. O capital se acumula a uma taxa de poupança fixa $s$ e deprecia a uma taxa $\delta$. A taxa do progresso tecnológico é dada por $g_{B}$. A força de trabalho cresce à taxa $n$.

A introdução das emissões no modelo é dada por $\Omega$, em que cada unidade $F$ da atividade econômica gera $\Omega$ unidades de poluição. Porém, a quantidade de poluição produzida vai depender da existência de práticas mitigadoras nas emissões de poluentes. Supõe-se que a prática mitigadora seja uma função com retornos constantes de escala e que a quantidade de poluição mitigada seja uma função estritamente côncava da atividade econômica $F$ e dos esforços de abatimento $F^{A}$. Se a prática de mitigação no nível $\Omega A$ remove unidades de poluição do total criado, então a poluição emitida é igual a poluição gerada menos a poluição mitigada. Assim,

2 Uma discussão sobre o problema de decisão acerca da adoção de práticas de mitigação pode ser encontrada, por exemplo, em Baumol e Oates (1988) e Perman et al. (2011). As medidas para mitigar a poluição englobam impostos de Pigou e permissões comercializáveis de emissões. O imposto de Pigou consiste em um imposto sobre as emissões de poluentes que procura internalizar os custos e fazer com que a firma venha a considerar as externalidades em seu processo interno de decisão de produção. A alíquota do imposto de Pigou é igual ao dano social marginal. As permissões comercializáveis de emissões são uma tentativa de obter o mesmo resultado do imposto de Pigou com o auxílio do mercado. A autoridade ambiental determina a quantidade agregada de emissões no montante em que o dano social marginal é igual ao custo marginal de mitigação. A seguir, emite permissões comercializáveis de emissões nesse montante e deixa a alocação das emissões entre fontes para o mercado. Considerando as curvas de dano social marginal e custo marginal de mitigação em um ambiente de certeza, a alíquota do imposto de Pigou é aquela que produz o montante permitido de emissões, de modo que o imposto de Pigou e as permissões comercializáveis de emissões produzem exatamente o mesmo resultado em termos práticos. Em um contexto de incerteza, a equivalência não permanece, e as duas práticas de mitigação podem produzir diferenças substanciais nos valores esperados do bem-estar social. A autoridade ambiental irá preferir, em um contexto de incerteza, uma política ou outra, dependendo da incerteza afetar o dano social marginal, o custo marginal de mitigação ou ambos. Para maiores detalhes, consultar Baumol e Oates (1988), cap. 5 e Perman et al. (2011), cap. 6. 


$$
E=\Omega F-\Omega A\left(F, F^{A}\right)
$$

Desta forma, combinando as hipóteses sobre a poluição e redução das emissões com o modelo de Solow, o produto $Y$ disponível para consumo ou investimento torna-se $Y=[1-\theta] F$. Neste caso $\theta$ representa a fração da atividade econômica destinada à mitigação. Supõe-se, ainda, que a taxa de progresso tecnológico seja exógena em relação à mitigação das emissões, o que faz com que $\Omega$ se reduza à taxa $g_{A}>0$.

As taxas de crescimento devem ser iguais ao longo da trajetória de crescimento equilibrado. À medida que a economia se encontra na trajetória de crescimento equilibrado, o produto agregado, consumo e capital crescem à taxa $g_{B}+n$, enquanto suas versões por trabalhador crescem à taxa $g_{B}$, isto é, $g_{y}=g_{k}=g_{c}=g_{B}>0$.

E quando a economia se encontra em seu estado estacionário, a taxa de crescimento das emissões agregadas é dada por $g_{E}=g_{B}+n-g_{A}$. A taxa de crescimento das emissões depende de um efeito escala $\left(g_{B}+n\right)$, e de um efeito técnica criado pelo impacto do progresso tecnológico no abatimento das emissões $\left(g_{A}\right)$. O crescimento sustentável ocorre quando a taxa de crescimento da emissões agregadas no equilíbrio é negativa $\left(g_{E}<0\right)$.

O modelo de Solow verde relaciona o nível de renda per capita e a qualidade ambiental produzindo uma trajetória conhecida como Curva Ambiental de Kuznets. Isso pode ser verificado por meio das taxas de crescimento das emissões agregadas e de variação do capital por trabalhador efetivo, dadas por:

$$
\begin{aligned}
& \frac{\dot{E}}{E}=g_{E}+\alpha \frac{\dot{k}}{k} \\
& \frac{\dot{k}}{k}=s k^{\alpha-1}(1-\theta)-\left(\delta+n+g_{B}\right)
\end{aligned}
$$

As duas expressões acima valem para qualquer ponto do tempo. Por meio delas, pode-se ligar a dinâmica da acumulação do capital à evolução dos níveis de poluição. A curva gerada desta relação é negativamente inclinada, e pode ser considerada um locus 
da poupança, uma vez que se desloca quando ocorre uma variação na taxa de poupança $s$. À medida que o capital por trabalhador efetivo aumenta, o locus da poupança se aproxima de zero.

A análise gráfica (Figura 2) permite mostrar que a taxa de variação do capital por trabalhador efetivo é positiva em pontos à esquerda de $B$, e negativa em pontos à direita. A intersecção no ponto $B$ gera o estado estacionário do capital por trabalhador efetivo $k^{*}$. Níveis de mais baixos e mais distantes do equilíbrio implicam um crescimento mais acelerado. Quando a economia entra em uma trajetória de crescimento equilibrado, a taxa de variação do capital por trabalhador efetivo é zero. Nesse ponto, o produto agregado da economia e o capital crescem à taxa $g_{B}+n$. Com relação às emissões, a taxa de crescimento é zero em $T$, positiva à esquerda e negativa à direita. Dessa forma, o ponto $T$ pode ser associado ao ponto de inflexão das emissões. Sob a hipótese de crescimento sustentável, o modelo gera a Curva Ambiental de Kuznets retratada no segundo gráfico da Figura 2.

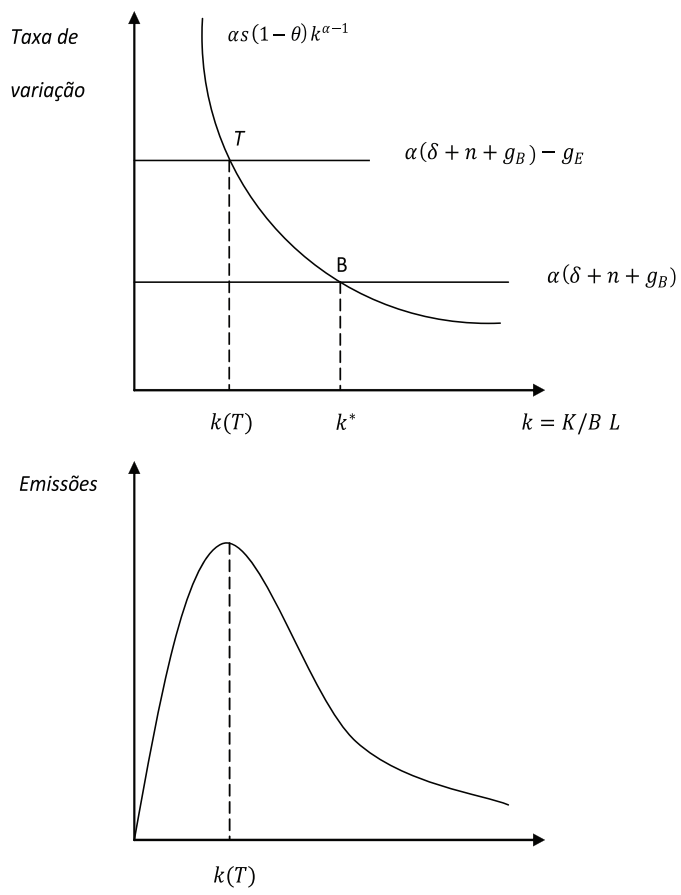

Figura 2 - Trajetória das emissões de poluentes

Fonte: Brock e Taylor (2010) 
Se o estoque inicial de capital em uma economia for baixo, então as emissões, em um primeiro momento, crescerão e, posteriormente, diminuirão. Se o estoque inicial de capital for alto, pode ocorrer uma queda monotônica das emissões à medida que a economia se move em direção ao equilíbrio.

$\mathrm{Na}$ especificação longa da equação, supõe-se que as taxas de progresso tecnológico são comuns a todos os países, e o conjunto de fatores que determinam o estado estacionário e a taxa de crescimento ao longo da trajetória de crescimento equilibrado varia entre os países. Assim, permitindo que $s_{i}, \theta_{i}$ e $\left(\delta+n+g_{B}\right)_{i}$ e sejam uma média temporal específica para cada país, a seguinte equação pode ser obtida:

$$
\begin{aligned}
& {[1 / N] \log \left[e_{i t}^{c} / e_{i t-N}^{c}\right]=\beta_{0}-\beta_{1} \log \left[e_{i t-N}^{c}\right]+\beta_{2} \log \left(s_{i}\right)+\beta_{3} \log \left(1-\theta_{i}\right)} \\
& -\beta_{4}\left[\log \left(\delta+n+g_{B}\right)_{i}\right]+u_{i t}
\end{aligned}
$$

em que o termo à esquerda é a taxa de crescimento das emissões em cada período, $s_{i t}$ é a poupança, $\theta_{i}$ é a taxa de mitigação e $\left(\delta+n+g_{B}\right)_{i t}$ é a taxa de depreciação efetiva.

De acordo com Brock e Taylor (2010), poupança e mitigação afetam a trajetória de crescimento das emissões e do produto e mudam as magnitudes do estado estacionário. Porém, não exercem impacto algum sobre a taxa de crescimento de longo prazo. Por sua vez, o crescimento tecnológico e o crescimento populacional, além de exercer impactos sobre a trajetória de crescimento das emissões e do produto e sobre os valores de equilíbrio, também alteram as taxas de crescimento de longo prazo.

\section{Metodologia e dados}

Neste trabalho serão utilizadas duas metodologias diferentes para estimação de dados em painel, uma vez que os modelos usam dimensões temporais diferentes. De acordo com Levin et al. (2002), para painéis de tamanho médio $(25<\mathrm{T}<250,10<\mathrm{N}<250)$, em que $\mathrm{T}$ se refere a dimensão temporal e $\mathrm{N}$ corresponde ao número de indivíduos, é recomendado o uso de testes de raiz unitária e demais 
procedimentos de séries temporais específicos para metodologia de painel. No entanto, para painéis em que $\mathrm{T}$ é pequeno (considerando $\mathrm{T}<25)$ e $\mathrm{N}$ é grande $(10<\mathrm{N}<250)$ pode-se aplicar a metodologia padrão de painel e não é necessário utilizar os procedimentos de séries temporais. Para o caso da CAK padrão, em que $\mathrm{N}=99$, e $\mathrm{T}=$ 37, será necessário o uso da metodologia de séries temporais. Já para modelo de Brock e Taylor (2010), como $\mathrm{N}=99$ e $\mathrm{T}=6$, não será necessário o uso das técnicas de séries temporais. Segue uma breve descrição dos procedimentos que serão aplicados neste trabalho.

\subsection{Testes de raiz unitária ${ }^{3}$}

Os testes de raiz unitária desenvolvidos para dados em painel, podem ser divididos em duas gerações de testes. A primeira geração assume a hipótese de independência em corte transversal, já a segunda geração permite que ocorra correlação entre estas unidades.

A ideia básica dos testes de raiz unitária em painel, assim como na análise convencional de séries temporais, é encontrar o valor do coeficiente autorregressivo de um modelo AR(1) como o descrito abaixo:

$$
y_{i t}=\rho_{i} y_{i, t-1}+x_{i t}^{\prime} \gamma_{i}+\varepsilon_{i t}
$$

em que $\mathrm{i}=1, \ldots, \mathrm{N}, \mathrm{t}=1, \ldots, \mathrm{T}, y_{i t}$ é a variável a ser testada e $\varepsilon_{i t}$ é um termo de erro estacionário. O termo $x_{i t}$ representa os componentes estocásticos e não estocásticos. $\mathrm{O}$ modelo (8) pode ser reescrito como uma regressão do tipo Dickey-Fuller Aumentado (ADF), da seguinte forma:

$$
\Delta y_{i t}=\varphi_{i} y_{i, t-1}+\sum_{z=1}^{p_{i}} \beta_{i, z} \Delta y_{i, t-z}+x_{i t}^{\prime} \gamma_{i}+\varepsilon_{i t}
$$

em que $\Delta y_{i t}=y_{i t}-y_{i t-1}, \varphi_{i}=1-\rho_{i}$ e as $p$ defasagens variam para cada setor.

3 Maiores detalhes em Breitung e Pesaram (2005).

Estud. Econ., São Paulo, vol.45, n.1, p. 97-126, jan.-mar. 2015 
A hipótese nula é a mesma para todos os testes: ${ }^{4}$

$$
H o: \varphi_{i}=0 \text {, para todo } \mathrm{i}=1, \ldots, \mathrm{N} \text {. }
$$

Ou seja, a hipótese nula é a de que todas as unidades do painel possuem raiz unitária. A peculiaridade dos testes de raiz unitária em painel é a presença de duas hipóteses alternativas diferentes:

$$
\begin{aligned}
& H_{1 a}: \varphi_{1}=\cdots=\varphi_{N}=\varphi \text { е } \varphi<0 \\
& H_{1 b}: \varphi_{1}<0, \ldots, \varphi_{N}<0, N_{0} \leq 0
\end{aligned}
$$

Sob a hipótese alternativa $H_{1 a}$ o componente autorregressivo é o mesmo para todas as unidades do painel, por isso é chamada de hipótese alternativa homogênea. Os testes de Levin, Lin e Chu (2002) e Breitung (2000) adotam este tipo de hipótese. A alternativa $H_{1 b}$, por sua vez, é chamada de alternativa heterogênea, já que não impõe um coeficiente autorregressivo específico para cada unidade de corte transversal. Os testes IPS, de Im, Pesaram e Shin (2003), Fisher ADF e Fisher PP, de Madalla e Wu (1999), Choi ADF e Choi PP, de Choi (2001), e CIPS, de Pesaram (2003), adotam este tipo de hipótese alternativa.

\subsection{Cointegração}

Uma vez verificado se as séries são estacionárias ou não, procede-se aos testes de cointegração em painel, a fim de verificar se a relação entre as séries não é espúria. Pedroni (1999) desenvolveu testes estatísticos seguindo a metodologia proposta por Engle e Granger (1987). O autor considerou a seguinte regressão:

$$
\begin{aligned}
& y_{i t}=\alpha_{i}+\delta_{i} t+\beta_{1} x_{1 i, t}+\beta_{2} x_{2 i, t}+\cdots+\beta_{M} x_{M i, t}+e_{i, t} \\
& \text { para } t=1, \ldots, T ; i=1, \ldots, N ; m=1, \ldots, M . \\
& \frac{{ }^{4} \text { Com exceção do teste Hadri (2000). }}{}
\end{aligned}
$$


Neste caso, $T$ se refere ao número de observações no tempo, $N$ se refere ao número de indivíduos no painel e $M$ se refere ao número de regressores incluídos na equação. Supõe-se que as variáveis $y_{i t} \mathrm{e}$ $x_{i, t}$ sejam integradas de ordem um (I(1)). Assim, como na análise de cointegração em séries temporais, o estabelecimento de relações de cointegração entre as séries é equivalente a mostrar que o termo de erro na Equação (13) é estacionário.

A hipótese nula associada ao procedimento do teste de Pedroni é que o resíduo possui raiz unitária, que é equivalente a supor que não existem relações de cointegração. Aqui também há duas hipóteses alternativas diferentes. A hipótese alternativa homogênea considera um mesmo coeficiente autorregressivo para o coeficiente $\rho$. Já a hipótese alternativa heterogênea não impõe que o coeficiente tem que ser o mesmo para todas as unidades de corte transversal. Uma limitação do teste de Pedroni é a hipótese de independência das unidades do painel. Assim como nos testes de raiz unitária em painel, o teste de Pedroni pode apresentar distorções de tamanho e poder na presença deste tipo de correlação.

A fim de evitar este tipo de problema, Westerlund (2007) desenvolveu um teste de cointegração baseado no método de correção dos erros, no qual a presença de dependência não afeta o tamanho e o poder do teste. $\mathrm{O}$ autor considerou o seguinte processo:

$$
\begin{aligned}
& y_{i t}=\Phi_{1 i}+\Phi_{2 i} t+Z_{i t} \\
& x_{i t}=x_{i t-1}+v_{i t}
\end{aligned}
$$

em que $t=1, \ldots, T$ e $i=1, \ldots, N$. O escalar $y_{i t}$ contém tanto termos deterministas $\left(\Phi_{1 i}+\Phi_{2 i} t\right)$ quanto um termo estocástico $Z_{i t}$.

A construção das estatísticas é feita sob a seguinte equação:

$\Delta y_{i t}=\delta_{i}^{\prime} d_{t}+\alpha_{i}\left(y_{i t-1}+\lambda_{i}^{\prime} x_{i t-1}\right)+\sum_{j=1}^{p_{i}} \alpha_{i j} \Delta y_{i t-j}+\sum_{j=0}^{p_{i}} \gamma_{i j} \Delta x_{i t-j}+e_{i t}(16)$

em que $d_{t}=(1, t)^{\prime}, \alpha_{i}$, é o parâmetro de correção dos erros e $\lambda_{i}=-\alpha_{i} \beta_{i}$. O parâmetro $\alpha_{i}$ não é afetado pela imposição de $\beta_{i}$, o que sugere a validade do teste sobre $\alpha_{i}$ para verificar a cointegração das séries. O teste faz uso de quatro estatísticas: duas desenvolvidas na versão pooled e duas construídas na versão group mean. A hipótese alternativa difere para as duas versões de estatísticas. 
Neste trabalho, optou-se por fazer dois testes de cointegração. Um baseado na primeira geração de testes e outro baseado na segunda geração. Espera-se, com isso, evitar que distorções no teste de Pedroni afetem a robustez das estimações.

\subsection{Estimação do vetor de cointegração}

Engle e Granger (1987) ${ }^{5}$ argumentam que se uma combinação linear de duas ou mais séries I(l) for estacionária, pode-se dizer que as séries cointegram, ou seja, apresentam uma relação de longo prazo. Neste trabalho serão utilizados estimadores de equações simples, a fim de se estimar a CAK.

Para uma melhor definição dos estimadores que serão utilizados, considere o seguinte modelo simples de efeitos fixos em painel:

$$
y_{i t}=\alpha_{i}+x_{i t}^{\prime} \beta+u_{i t}
$$

em que $\left\{y_{i t}\right\}$ é uma sequência de escalares, $\beta$ é um vetor (KX l) de parâmetros e $\left\{\alpha_{i}\right\}$ são os interceptos individuais de cada unidade de corte transversal. Se o termo de erro $\left\{u_{i t}\right\}$ for estacionário, então a cointegração de $y_{i t}$ e $x_{i t}$ prevalece para todos os indivíduos do painel. Neste caso, a Expressão (17) descreve um sistema de regressões cointegradas, em que $\left\{\boldsymbol{x}_{i t}\right\}$ é um processo integrado de ordem 1 para todo i:

$$
x_{i t}=x_{i t-1}+\varepsilon_{i t}
$$

em que $\varepsilon_{i t}$ é i.i.d com média zero e variância constante.

Breitung e Pesaram (2005) argumentam que, mesmo sob as fortes hipóteses que garantem a consistência, o estimador MQO se torna ineficiente, devido à endogeneidade dos regressores e à correlação serial dos resíduos.

A fim de corrigir o problema de endogeneidade dos regressores e correlação serial dos resíduos ${ }^{6}$ e fornecer estimativas consistentes e eficientes do vetor de cointegração, foram desenvolvidos estimadores

5 Engle, R.F.; Granger, C.W.J. Cointegration and error correction: representation, estimation, and testing. Econometrica, v.55, n.2, pp.251-76, 1987.

6 Decorrente da estimação da Equação (25) via Mínimos Quadrados Ordinários (MQO). 
alternativos. Entre eles, pode-se citar os estimadores Fully-Modified OLS (FM-OLS) e Dynamic OLS (DOLS), que serão utilizados neste trabalho. O estimador FM-OLS, proposto por Pedroni (2000), ajusta os efeitos da endogeneidade dos regressores e da dinâmica de curto prazo dos resíduos. Para corrigir o efeito da endogeneidade de longo prazo dos regressores, a variável dependente é ajustada pela parte do erro que é correlacionada com o regressor.

Outra forma de correção da endogeneidade e correlação serial dos resíduos é feita por meio do estimador DOLS. A versão group-means do estimador foi proposta por Pedroni (2000). A correção paramétrica feita pelo estimador ocorre pela inclusão de $p$ valores defasados e $p$ valores precedentes de $\Delta x_{i t}$, como regressores adicionais.

\subsection{Painel dinâmico}

Considere a seguinte especificação de um modelo de painel dinâmico:

$$
y_{i t}=\alpha_{i}+\gamma y_{i, t-1}+\beta x_{i t}+\eta_{t}+v_{i t}
$$

em que $y_{i t}$ representa a variável dependente, $y_{i, t-1}$ é a variável dependente defasada em um período e $\boldsymbol{x}_{i t}$ são os regressores adicionais. Finalmente, $\alpha_{i}$ e $\eta_{t}$ são termos de efeitos individual e temporal, e $v_{i t}$ é um termo de erro.

Em um painel dinâmico, a estimação, via OLS, dos coeficientes $\gamma$ e $\beta$ é enviesada e inconsistente. Isto ocorre pelo fato de que o regressor $y_{i, t-1}$ é correlacionado com $\alpha_{i}$ e possivelmente com o termo de erro composto $\left(\alpha_{i}+v_{i t}\right)$. Mesmo em um painel com efeitos fixos, a estimação é enviesada, uma vez que a hipótese de exogeneidade não pode ser verificada (Cameron e Trivedi, 2005).

Para contornar esse problema, diversos autores sugerem o uso de variáveis instrumentais, a fim de lidar com o problema da endogeneidade causada pelo regressor defasado. Os estimadores de painel dinâmico utilizam um modelo transformado em primeiras diferenças dado por:

$y_{i t}-y_{i, t-1}=\gamma\left(y_{i, t-1}-y_{i, t-2}\right)+\beta\left(x_{i t}-x_{i t-1}\right)+\left(v_{i t}-v_{i t-1}\right)$ 
Anderson e Hsiao (1981) ${ }^{7}$ sugerem o uso de $y_{i, t-2}$ como instrumento para $\left(y_{i, t-1}-y_{i, t-2}\right)$. Segundo os autores, este é um instrumento válido, já que não é correlacionado $\operatorname{com}\left(v_{i t}-v_{i t-1}\right)$, desde que os resíduos não exibam correlação serial. Segundo Islam (2003) a desvantagem deste método é a perda de duas unidades de corte transversal. Outra forma alternativa e mais eficiente, segundo Anderson e Hsiao (1981), é utilizar $\Delta y_{i, t-2}$ como instrumento para $\Delta y_{i, t-1}$. Já Arellano e Bond $(1991)^{8}$ propõem o uso de todas as defasagens da variável dependente como instrumento no modelo de painel dinâmico, por meio de um GMM em primeira diferença.

Porém, Arellano e Bover (1995) e Blundell e Bond (1998) argumentam que, apesar de eficientes, os instrumentos utilizados pelos modelos anteriores são fracos, principalmente se a variável apresentar forte persistência. Uma alternativa é utilizar um sistema que combina equações em nível e equações em primeira diferença (SystemGMM). Os instrumentos para a equação em primeira diferença são os mesmos descritos anteriormente e os instrumentos para a equação em nível são as diferenças defasadas das respectivas variáveis.

O estimador obtido depende da ausência de correlação serial de segunda ordem nos resíduos. Então se aplica um teste de autocorrelação de primeira ordem e outro de segunda ordem nos resíduos em primeira diferença. E para testar a validade dos instrumentos aplica-se o teste de Hansen e o teste de Sargan.

Apud Islam (1995).

Apud Islam (2003). 


\subsection{Dados}

Para se fazer a análise pretendida neste trabalho, os dados anuais obtidos correspondem ao período 1972-2008. A amostra contém 99 países que foram escolhidos em função da disponibilidade dos dados. Para o cálculo do modelo de convergência foram considerados seis ${ }^{9}$ pontos de corte transversal, referentes aos anos 1978, 1984, 1990, 1996, 2002 e 2008.

- Emissóes per capita de $\mathrm{CO}_{2}\left(\boldsymbol{e}_{\boldsymbol{i}}\right)$ : foram obtidas por meio da International Energy Agency (IEA), Medidas em toneladas métricas. As estimações de $\mathrm{CO}_{2}$ calculadas pela IEA representam o total das emissões de combustíveis fósseis. ${ }^{10}$

- Renda per capita $\left(\boldsymbol{y}_{i t}\right)$ : é medida pelo PIB real per capita, corrigido pela paridade do poder de compra. A variável foi coletada na Penn World Table, versão 7.0, divulgada em 2011.

- Taxa média de crescimento das emissões per capita $\left(\Delta e_{i t}\right)$ : foi construída seguindo a especificação proposta por Brock e Taylor (2010). Nesta especificação, obtém-se uma aproximação da taxa média de crescimento exata.

- Poupança per capita $\left(\boldsymbol{s}_{\boldsymbol{i t}}\right)$ : foi medida pela taxa de investimento disponível na Penn World Table, versão 7.0. O uso desta taxa pode ser justificado pela hipótese utilizada no modelo de Solow de que a economia é fechada. A mesma taxa é utilizada por Barro e Sala-i-Martin (2004, p. 519).

- Taxa de depreciação efetiva $\left(\boldsymbol{\delta}+\boldsymbol{n}+\boldsymbol{g}_{\boldsymbol{B}}\right)_{\boldsymbol{i t}}$ : também foi construída seguindo Brock e Taylor (2010). A taxa de crescimento populacional foi obtida junto ao Banco Mundial. Segundo Romer (2001), a taxa de depreciação $(\delta)$ varia entre $1 \%$ e $2 \%$. Já a taxa de crescimento tecnológico $\left(g_{B}\right)$ varia entre $3 \%$ e $4 \%$. Assim, Brock e Taylor (2010) consideraram $\left(\delta+g_{B}\right)$ equivalente a $5 \%$. Desta forma, a taxa de depreciação efetiva será composta da média do crescimento populacional de cada período considerado, acrescido de 0,05 para cada média calculada.

9 Conforme Islam (2003), a frequência estimada em vários estudos de painel é definida por um intervalo de cinco anos, porém, em função da quantidade de dados, optou-se por definir um intervalo de seis anos a fim de incorporar na análise o maior intervalo temporal possível entre a primeira e a última observação.

${ }^{10} \mathrm{O}$ banco de dados CAIT (Climate Analysis Indicators Tool), elaborado pelo World Resources Institute (WRI), poderia ser usado alternativamente para essa análise. Ele possui a vantagem de estar disponível publicamente pela internet no sítio http://cait2.wri.org/wri, ao contrário da base da IEA. Ambas as bases possuem alta confiabilidade. Neste artigo optamos por usar o banco de dados do IEA. 
A seguir serão reportadas informações a respeito da base de dados. A Tabela 1 mostra a estatística descritiva das variáveis e o quadro 1 mostra quais foram os países utilizados na amostra.

Tabela 1- Estatística Descritiva das Variáveis

\begin{tabular}{|c|c|c|c|c|c|c|c|c|c|c|c|}
\hline \multicolumn{2}{|c|}{ Variável } & \multirow{2}{*}{$\begin{array}{c}\text { Média } \\
0,577\end{array}$} & \multirow{2}{*}{$\begin{array}{c}\begin{array}{c}\text { Desvio } \\
\text { Padrão }\end{array} \\
1,579\end{array}$} & \multirow{2}{*}{$\begin{array}{c}\text { Min. } \\
-3,910\end{array}$} & \multirow{2}{*}{$\begin{array}{l}\text { Max. } \\
3,848\end{array}$} & \multicolumn{2}{|c|}{ Variável } & \multirow{2}{*}{$\begin{array}{c}\text { Média } \\
0,006\end{array}$} & \multirow{2}{*}{$\begin{array}{c}\text { Desvio } \\
\text { Padrão } \\
0,019\end{array}$} & \multirow{2}{*}{$\begin{array}{l}\text { Min. } \\
-0,082\end{array}$} & \multirow{2}{*}{$\begin{array}{l}\text { Max. } \\
0,111\end{array}$} \\
\hline $\boldsymbol{e}_{i t}$ & Overall & & & & & & Overall & & & & \\
\hline & Between & & 1,553 & $-3,118$ & 3,270 & & Between & & 0,009 & $-0,022$ & 0,044 \\
\hline & Within & & 0,324 & $-1,875$ & 1,793 & & Within & & 0,016 & $-0,069$ & 0,089 \\
\hline \multirow{3}{*}{$y_{i t}$} & Overall & 8,654 & 1,274 & 4,767 & 11,64 & \multirow{3}{*}{$\overline{\boldsymbol{e}}_{\boldsymbol{i t}}$} & Overall & 0,584 & 1,572 & $-3,778$ & 3,671 \\
\hline & Between & & 1,250 & 5,404 & 11,02 & & Between & & 1,551 & $-3,120$ & 3,273 \\
\hline & Within & & 0,273 & 7,268 & 10,17 & & Within & & 0,293 & $-0,947$ & 1,602 \\
\hline \multirow{3}{*}{$y_{i t}^{2}$} & Overall & 76,52 & 21,62 & 22,73 & 135,41 & \multirow{3}{*}{$s_{i t}$} & Overall & $-1,573$ & 0,464 & $-3,838$ & $-0,501$ \\
\hline & Between & & 21,21 & 29,23 & 121,45 & & Between & & 0,408 & $-3,334$ & $-0,719$ \\
\hline & Within & & 4,73 & 56,59 & 100,07 & & Within & & 0,224 & $-2,745$ & $-0,372$ \\
\hline \multirow{3}{*}{$y_{i t}^{3}$} & Overall & 689,68 & 281,73 & 108,34 & $1.575,74$ & \multirow{3}{*}{$\boldsymbol{d e p}_{i t}$} & Overall & $-2,712$ & 0,165 & $-3,202$ & $-2,282$ \\
\hline & Between & & 275,72 & 158,26 & $1.339,46$ & & Between & & 0,149 & $-3,070$ & $-2,462$ \\
\hline & Within & & 64,01 & 421,97 & 966,86 & & Within & & 0,071 & $-3,077$ & $-2,496$ \\
\hline
\end{tabular}

Fonte: Elaborado pelos autores

Overall: estatística que engloba todas as unidades de corte transversal; Between: estatística calculada entre os grupos; Within: estatística calculada dentro dos grupos.

Todas as variáveis estão em logaritmos, exceto a variável $\Delta \boldsymbol{e}_{i t}$.

Quadro 1 - Países constantes da amostra

\begin{tabular}{llllll}
\hline África do Sul & Canadá & Finlândia & Israel & Omã & Sudão \\
Albânia & Chile & França & Itália & Panamá & Suécia \\
Alemanha & China & Gabão & Jamaica & Paquistão & Suíça \\
Angola & Chipre & Gana & Japão & Paraguai & Tailândia \\
Argélia & Cingapura & Grécia & Jordânia & Peru & Tanzânia \\
Argentina & Colômbia & Guatemala & Líbano & Polônia & Togo \\
Austrália & Congo & Haiti & Luxemburgo & Portugal & Trinidad Tobago \\
Áustria & Costa Rica & Holanda & Malásia & Quênia & Tunísia \\
Bahrein & Costa do Marfim & Honduras & Malta & Reino Unido & Turquia \\
Bangladesh & Cuba & Hong Kong & Marrocos & R.D. Congo & Uruguai \\
Bélgica & Dinamarca & Hungria & México & Rep. Dominicana & Venezuela \\
Benin & Egito & Índia & Moçambique & Romênia & Vietnam \\
Bolívia & El Salvador & Indonésia & Nepal & Senegal & Zâmbia \\
Brasil & Equador & Irã & Nicarágua & Singapura & Zimbábue \\
Brunei & Estados Unidos & Iraque & Nigéria & Síria & \\
Bulgária & Etiópia & Irlanda & Noruega & Espanha & \\
Camarões & Filipinas & Islândia & Nova Zelândia & Sri Lanka & \\
\hline
\end{tabular}

Fonte: Elaborado pelos autores 


\section{Resultados}

A presente seção pretende mostrar os resultados do trabalho. Uma vez que foram utilizados dois modelos diferentes, CAK e modelo de Brock e Taylor (2010), foi necessário o uso de duas metodologias distintas: séries temporais em painel e modelos de painel curto. Por isso, optou-se por apresentar os resultados divididos em duas seções. A primeira seção traz todos os resultados e estimações para a CAK. Já a segunda seção traz os resultados do modelo de Brock e Taylor (2010).

\subsection{Curva Ambiental de Kuznets}

Quando se trata da análise de cointegração, o primeiro passo é verificar se as séries são não estacionárias por meio de testes de raiz unitária. Os testes aqui reportados adotam a hipótese alternativa heterogênea com a especificação mais geral (tendência e intercepto). ${ }^{11}$ Sob esta hipótese, a rejeição de $\mathrm{H}_{0}$, implica que parte das séries é estacionária. ${ }^{12}$ Desta forma, a Tabela 2 reporta os resultados dos seguintes testes: IPS, Fisher ADF, Fisher PP, Choi ADF, Choi PP, representando a primeira geração de testes. Já o teste CIPS é o teste representativo da segunda geração.

Tabela 2 - Testes de Raiz Unitária: intercepto e tendência

\begin{tabular}{c|cccc}
\hline Teste & $\boldsymbol{e}_{\boldsymbol{i t}}$ & $\boldsymbol{y}_{\boldsymbol{i t}}$ & $\boldsymbol{y}_{\boldsymbol{i t}}^{\mathbf{2}}$ & $\boldsymbol{y}_{\boldsymbol{i t}}^{\mathbf{3}}$ \\
\hline \multirow{2}{*}{ IPS } & 2,627 & 7,378 & 8,194 & 8,624 \\
& $\mathbf{0 , 9 9 5 7}$ & $\mathbf{1 , 0 0 0 0}$ & $\mathbf{1 , 0 0 0 0}$ & 1,0000 \\
Fisher ADF & 172,677 & 106,717 & 98,469 & 97,276 \\
& $\mathbf{0 , 0 2 7}$ & $\mathbf{1}, 0000$ & $\mathbf{1 , 0 0 0 0}$ & $\mathbf{1 , 0 0 0 0}$ \\
Fisher PP & 272,706 & 132,240 & 126,556 & 121,743 \\
& $\mathbf{0 , 0 0 0 3}$ & $\mathbf{0 , 9 9 9 9}$ & $\mathbf{1 , 0 0 0 0}$ & $\mathbf{1 , 0 0 0 0}$ \\
Choi ADF & 3,031 & 8,214 & 8,918 & 9,208 \\
& $\mathbf{0 , 9 9 8 8}$ & $\mathbf{1 , 0 0 0 0}$ & $\mathbf{1 , 0 0 0 0}$ & $\mathbf{1 , 0 0 0 0}$ \\
Choi PP & $-1,034$ & 5,575 & 6,306 & 7,074 \\
& $\mathbf{0 , 1 5 0 6}$ & $\mathbf{1 , 0 0 0 0}$ & $\mathbf{1 , 0 0 0 0}$ & $\mathbf{1 , 0 0 0 0}$ \\
CIPS & $-2,195$ & $-2,413$ & $-1,996$ & -1.962 \\
& $\mathbf{0 , 6 5 3}$ & $\mathbf{0 , 1 7 4}$ & $\mathbf{1 , 0 0 0 0}$ & $\mathbf{0 , 9 7 6}$ \\
\hline
\end{tabular}

Fonte: elaborado pelos autores.

p-valor em negrito

Valores críticos: IPS : $-2,37,-2,45,-2,28$ com nível de significância 1\%, 5\% e 10\% respectivamente CIPS: $-2,65,-2,56,-2,51$ com nível de significância 1\%, 5\% e 10\% respectivamente

${ }^{11}$ Foram feitos testes nas demais especificações (intercepto e passeio aleatório), que apontaram para a presença de raiz unitária.

12 Pois $\mathrm{H}_{0}$ : as séries possuem raiz unitária. 
De modo geral, os testes apontam para a presença de raiz unitária nas séries. A exceção fica por conta dos testes Fisher ADF e Fisher PP, que apontaram para a estacionariedade da variável emissões. No entanto, esses testes pressupõem independência entre as unidades do painel e, conforme ressalta Baltagi (2005), apresentam distorções de tamanho quando $\mathrm{N}=100$. E é exatamente o que se verifica para amostra em questão, uma vez que $N=99$. Além do mais, o teste CIPS, que relaxa a suposição de independência, não rejeitou a hipótese de raiz unitária. Desta forma, para a especificação geral (intercepto e tendência), os testes apontaram para a presença de raiz unitária nas séries.

Uma vez verificado que as séries apresentam raiz unitária e são integradas de mesma ordem, ${ }^{13}$ parte-se agora para os testes de cointegração. O teste de Pedroni apresenta três estatísticas de painel e três estatísticas de grupo. ${ }^{14} \mathrm{~A}$ hipótese nula do teste é ausência de cointegração. Logo, verifica-se cointegração entre as variáveis quando se rejeita a hipótese nula. A equação de cointegração foi especificada admitindo-se apenas uma constante.

Daqui em diante serão considerados dois modelos: um modelo com os termos renda e renda ao quadrado; e um modelo com os termos renda, renda ao quadrado e renda ao cubo.

Modelo 1: $\ln e_{i t}=\alpha_{i}+\beta_{1} \ln y_{i t}+\beta_{2}\left(\ln y_{i t}\right)^{2}+u_{i t}$

Modelo 2: $\ln e_{i t}=\alpha_{i}+\beta_{1} \ln y_{i t}+\beta_{2}\left(\ln y_{i t}\right)^{2}+\beta_{3}\left(\ln y_{i t}\right)^{3}+u_{i t}$

\footnotetext{
${ }^{13}$ Foram feitos os mesmos testes sobre a primeira diferença das variáveis, porém optou-se por não reportá-los neste trabalho. Os testes apontaram que todas as variáveis são estacionárias na primeira diferença.

${ }^{14}$ Optou-se por não reportar a estatística v, uma vez que os resultados foram próximos aos da estatística rho, e também porque podem existir distorções de tamanho e poder devido à dimensão das séries utilizadas neste trabalho.
} 
Tabela 3 - Teste de cointegração de Pedroni

\begin{tabular}{|c|c|c|c|c|}
\hline & Painel & & Grupo & \\
\hline \multirow[t]{6}{*}{ Modelo 1} & \multirow{2}{*}{ rho } & 0,3394 & \multirow{2}{*}{ rho } & 1,0435 \\
\hline & & 0,6328 & & 0,8516 \\
\hline & \multirow{2}{*}{ PP } & $-2,1012$ & \multirow{2}{*}{ PP } & $-3,7313$ \\
\hline & & 0,0178 & & 0,0001 \\
\hline & \multirow{2}{*}{ ADF } & $-1,6090$ & \multirow{2}{*}{ ADF } & $-4,0041$ \\
\hline & & 0,0538 & & 0,0000 \\
\hline \multirow[t]{6}{*}{ Modelo 2} & \multirow{2}{*}{ rho } & 1,4292 & \multirow{2}{*}{ rho } & 2,6466 \\
\hline & & 0,9997 & & 0,9959 \\
\hline & \multirow{2}{*}{ PP } & $-1,6044$ & \multirow{2}{*}{ PP } & $-3,0302$ \\
\hline & & 0,0543 & & 0,0012 \\
\hline & \multirow{2}{*}{ ADF } & $-2,0835$ & \multirow{2}{*}{ ADF } & $-4,0265$ \\
\hline & & 0,0186 & & 0,0000 \\
\hline
\end{tabular}

Fonte: elaborado pelos autores.

p-valor em negrito.

O teste de cointegração de Pedroni apresentou alguns resultados aparentemente contraditórios. Enquanto a estatística rho não foi estatisticamente significante, as demais estatísticas apontam para rejeição da hipótese nula, pelo menos a 10\% de significância para as estatísticas de painel. Já utilizando as estatísticas de Grupo, rejeitouse a hipótese nula a $1 \%$, com exceção novamente da estatística rho.

Pedroni (2004) argumenta que a estatística rho tende a ter bom poder para painéis com $\mathrm{N}$ pequeno e $\mathrm{T}$ relativamente grande. Desta forma, o autor adverte que este é um caso extremo, e que em situações diferentes desta, as demais estatísticas tendem a se adequar melhor. Além do mais, os testes assumem independência entre as unidades do painel, caso isso não ocorra os testes podem ter problemas de tamanho e poder.

Uma vez que podem existir problemas de distorção e tamanho no teste de Pedroni em virtude da suposição de independência das unidades do painel, optou-se por realizar outro teste de cointegração. O teste de Westerlund (2007) permite que se faça a correção deste problema usando estatísticas robustas, obtidas por meio do método de bootstrap. ${ }^{15}$

15 Foram feitas 1.000 replicações. 
Tabela 4 - Testes de cointegração de Westerlund

\begin{tabular}{|c|c|c|}
\hline Estatística & Modelo 1 & Modelo 2 \\
\hline \multirow{2}{*}{$\mathbf{G}_{\tau}$} & $-1,954^{* * *}$ & $-1,861^{* * *}$ \\
\hline & 0,0000 & 0,0000 \\
\hline \multirow{2}{*}{$\mathbf{G}_{a}$} & $-6,007^{\star \star * *}$ & $-3,604^{\star \star \star}$ \\
\hline & 0,0000 & 0,0000 \\
\hline \multirow[b]{2}{*}{$\mathbf{P} \tau$} & $-14,008^{* \star \star}$ & $-10,889^{\star \star \star}$ \\
\hline & 0,0000 & 0,0000 \\
\hline $\mathbf{P}_{a}$ & $\begin{array}{c}-4,596^{* * *} \\
\end{array}$ & $\begin{array}{c}-2,947^{\star \star *} \\
\end{array}$ \\
\hline
\end{tabular}

Fonte: elaborado pelos autores

$* * *, * *,{ }^{*}$ indicam significância de $1 \%, 5 \%$ e $10 \%$ respectivamente p-valor em negrito

Os resultados indicam a existência de cointegração a $1 \%$ de significância. Uma vez que o teste permite a correlação entre os indivíduos do painel, os resultados são mais robustos do que aqueles reportados pelo teste de Pedroni. De qualquer forma, ambos os testes apresentaram indícios de que as variáveis são cointegradas.

Para avaliar a ocorrência da relação no formato de $U$ invertido, foram utilizados os estimadores FMOLS e DOLS, ambos na versão group-mean. De acordo com Tabela 5, pode-se verificar que todos os coeficientes estimados foram significantes e apresentaram os sinais esperados pela teoria.

Tabela 5 - Estimação do vetor de cointegração

\begin{tabular}{|c|c|c|c|c|}
\hline \multirow[b]{2}{*}{ Variável } & \multicolumn{2}{|c|}{ Modelo 1} & \multicolumn{2}{|c|}{ Modelo 2} \\
\hline & FMOLS & DOLS & FMOLS & DOLS \\
\hline \multirow{2}{*}{$y_{i t}$} & $1,63^{* *}$ & $1,739^{* \star}$ & $3,84^{\star *}$ & $2,851^{\star *}$ \\
\hline & $(13,67)$ & $(15,48)$ & $(3,93)$ & $(3,84)$ \\
\hline \multirow{2}{*}{$y_{i t}^{2}$} & $-0,06^{\star \star}$ & $-0,059^{\star *}$ & $-0,22^{* *}$ & $-0,130^{\star *}$ \\
\hline & $(-134.21)$ & $(-135,25)$ & $(-8,28)$ & $(-8,25)$ \\
\hline \multirow{2}{*}{$y_{i t}^{3}$} & - & - & $0,003^{* *}$ & $0,0008^{* *}$ \\
\hline & & & $-108,51$ & $(-109,26)$ \\
\hline Ponto de Inflexão & $792.805,60$ & $2.513 .755,00$ & $6.168,88$ & $57.837,04$ \\
\hline
\end{tabular}

Fonte: elaborado pelos autores.

Estatística $t$ entre parênteses.

***, $* *,{ }^{*}$ indicam significância de $1 \%, 5 \%$ e $10 \%$ respectivamente.

O procedimento de análise da estimação de uma CAK compreende a análise dos sinais das variáveis explicativas e da magnitude do coeficiente da renda ao cubo. Segundo Grossman e Krueger (1995) nenhuma inferência pode ser feita a respeito da relação entre os valores dos coeficientes das variáveis explicativas com a variável dependente. 
Em ambos modelos, os sinais dos coeficientes são os esperados pela teoria. No modelo 2, que inclui a renda ao cubo como variável explicativa adicional, temos que o coeficiente dessa variável está bem próximo de zero, mas significativo, o que aponta para uma curva do tipo $\mathrm{N}$ com a segunda inflexão bem suave, quando a equação é estimada pelo método FMOLS. Porém, quando a equação é estimada pelo método DOLS, o valor é ainda mais próximo de zero.

Já os pontos de inflexão apresentaram uma grande diferença entre os dois modelos. No modelo 1, a renda per capita necessária para que as emissões passem a apresentar uma trajetória declinante é de US\$ 792.805,6 quando estimado pelo método FMOLS. Já a estimação por meio do método DOLS apresentou um ponto de inflexão ainda mais elevado: US\$2.513.755,00. Ambos os valores são extremamente elevados e muito distantes da realidade. Porém, o ponto de inflexão do modelo 2 é mais razoável do que o anterior. O nível de renda per capita de U\$S 6.168,88 não é tão elevado quando se confronta com os resultados de Cole et al. (1997) que foi de U\$S 25.100,00. Porém, foi superior aos resultados de Shafik e Bandyopadhyay (1992), que oscilou entre US\$3.000,00 e U\$S 4.000,00. Mesmo quando se considera o ponto de inflexão obtido por meio do método DOLS, um valor US\$57.837,04 é razoável quando se compara com resultados obtidos anteriormente. Por exemplo, Wagner (2008) encontrou diversos pontos de inflexão de acordo com o método utilizado. Os pontos de inflexão obtidos variaram entre US\$13.090,00 e US\$ 394.449,00.

Desta forma, a ocorrência do movimento descrito pela CAK está condicionada ao nível de renda. Ou seja, de acordo com a teoria, as emissões cairão a partir do momento em que a renda alcançar o ponto de inflexão.

O objetivo desta estimação é apenas confrontá-la com os resultados obtidos do modelo de Brock e Taylor (2010). Por isso, foram utilizados apenas dois tipos de estimadores e um modelo tradicional, cuja escolha dos estimadores estava condicionada às equações a serem testadas. Como o foco do trabalho é estimar um modelo alternativo à $\mathrm{CAK}$, a discussão a respeito desta metodologia não será levada adiante. 


\subsection{Modelo de Convergência das emissões (Brock e Taylor, 2010)}

Preliminarmente, foram feitos os testes de poolabilidade, o teste de Hausman e correlação serial. Quanto ao teste de poolabilidade, ${ }^{16}$ segundo Baltagi (2005), o procedimento do teste consiste em comparar um modelo de MQO com um modelo que utiliza a metodologia de painel. ${ }^{17}$ A rejeição da hipótese nula implica a necessidade de se aplicar métodos de painel na estimação do modelo a ser estudado. Já o teste de Hausman consiste na escolha entre dois estimadores: Efeitos Fixos e Efeitos Aleatórios. Sob $\mathrm{H}_{0}$ ambos estimadores são consistentes e eficientes. Já sob a hipótese alternativa, apenas o estimador de Efeitos Fixos é consistente.

Tabela 6 - Testes Preliminares

\begin{tabular}{ccc}
\hline Testes & Convergência Absoluta & Convergência condicional \\
\hline \multirow{2}{*}{ Teste Poolabilidade } & 1,331 & 2,5167 \\
& $\mathbf{0 , 0 3 0 6}$ & $\mathbf{0 , 0 0 0 2}$ \\
Teste de Hausman & 132,11 & 156,37 \\
& $\mathbf{0 , 0 0 0 0}$ & $\mathbf{0 , 0 0 0 0}$ \\
Teste de Correlação Serial & 22,5514 & 0,9432 \\
& $\mathbf{0 , 0 0 0 0}$ & $\mathbf{0 , 3 3 1 4}$ \\
\hline
\end{tabular}

Fonte: elaborado pelos autores

p-valor em negrito

Conforme a Tabela 6, os resultados dos testes de poolabilidade apontaram para o uso da metodologia de painel por meio do estimador de efeitos fixos, já que o teste de Hausman apontou para a rejeição da hipótese nula. Quanto à correlação serial, pode-se verificar que ela ocorre no modelo de convergência absoluta. Por isso, foram estimadas regressões robustas à heterocedasticidade e correlação serial pelo procedimento de Windmeijer (2005). Na estimação do modelo de convergência com efeitos fixos foram usadas as Equações (23) para convergência absoluta e (24) para convergência condicional: ${ }^{18}$

$$
\begin{aligned}
& \qquad e_{i t}=\alpha_{i t}+\beta_{1}\left(e_{i, t-6}\right)+\varepsilon_{i t} \\
& \Delta e_{i t}=\alpha_{i t}+\beta_{1}\left(e_{i, t-6}\right)+\beta_{2}\left(s_{i t}\right)+\beta_{3}\left(\delta+n+g_{B}\right)_{i t}+\varepsilon_{i t} \\
& { }_{16} \text { Poolabilidade pode ser entendida como a reunião ou empilhamento dos dados. Sendo as- } \\
& \text { sim, consiste em impor um mesmo parâmetro para todas as unidades do painel ao longo do } \\
& \text { tempo. } \\
& { }^{17} \text { No teste feito neste trabalho, a hipótese alternativa foi um modelo de Efeitos Fixos. } \\
& { }^{18} \text { Todas as variáveis estão expressas em logaritmos, exceto } \Delta \boldsymbol{e}_{i t} .
\end{aligned}
$$

\footnotetext{
${ }^{16}$ Poolabilidade pode ser entendida como a reunião ou empilhamento dos dados. Sendo assim, consiste em impor um mesmo parâmetro para todas as unidades do painel ao longo do tempo.

${ }^{17}$ No teste feito neste trabalho, a hipótese alternativa foi um modelo de Efeitos Fixos.

${ }^{18}$ Todas as variáveis estão expressas em logaritmos, exceto $\Delta \boldsymbol{e}_{\boldsymbol{i t}}$.
} 
Para calcular o modelo por meio do método System-GMM, as Equações (22) e (23) foram reescritas da seguinte forma: ${ }^{19}$

$$
\begin{aligned}
& e_{i t}=\beta_{0}+\gamma e_{i t-1}+\varepsilon_{i t} \\
& e_{i t}=\beta_{0}+\gamma e_{i t-1}+\beta_{2} s_{i t}+\beta_{3}\left(\delta+n+g_{B}\right)_{i t}+\varepsilon_{i t}
\end{aligned}
$$

em que $\gamma=1+\beta_{1}$ e a convergência ocorre quando $\gamma<1$, pois para que ocorra a convergência é necessário que $\beta_{1}$ seja negativo. ${ }^{20}$

De acordo com a Tabela 7, as estimações apontaram para a existência de convergência. Embora, a estimação da convergência absoluta tenha sido estatisticamente significante, prevalece a convergência condicional, uma vez que a adição de variáveis explicativas com significância estatística é um indício a favor da convergência condicional.

\begin{tabular}{|c|c|c|c|c|}
\hline \multirow[b]{2}{*}{ Variável } & \multicolumn{2}{|c|}{ Efeitos Fixos } & \multicolumn{2}{|c|}{ System-GMM } \\
\hline & $\begin{array}{l}\text { Convergência } \\
\text { Absoluta }\end{array}$ & $\begin{array}{c}\text { Convergência } \\
\text { Condicional }\end{array}$ & $\begin{array}{l}\text { Convergên- } \\
\text { cia Absoluta }\end{array}$ & $\begin{array}{l}\text { Convergência } \\
\text { Condicional }\end{array}$ \\
\hline \multirow[t]{2}{*}{$\boldsymbol{e}_{i t-N}$} & $-0,024^{\star \star \star}$ & $-0,026^{\star \star \star}$ & $-0,645^{\star \star \star}$ & $-0,361^{\star \star \star}$ \\
\hline & $(-8,49)$ & $(-11,40)$ & $(2,28)$ & $(5,07)$ \\
\hline \multirow[t]{2}{*}{$s_{i t}$} & - & $0,015^{\star \star \star}$ & - & $1,437^{\star \star \star}$ \\
\hline & & $(4,24)$ & & $(6,26)$ \\
\hline \multirow[t]{2}{*}{$\left(\delta+n+g_{B}\right)_{i t}$} & & $-0,019^{*}$ & & $-2,493^{* *}$ \\
\hline & & $(-1,76)$ & & $(-2,09)$ \\
\hline$N$ & 594 & 594 & 495 & 495 \\
\hline$N^{o}$ de instrumentos & - & - & 8 & 19 \\
\hline Inst. Eq. diferenças & - & - & $e_{i t-2}, e_{i t-3}$ & $\boldsymbol{e}_{i t}, \boldsymbol{e}_{i t-1}, \boldsymbol{e}_{i t-2}, \boldsymbol{e}_{i t-3}, \boldsymbol{e}_{i t-4}$ \\
\hline Inst. Eq. Nível & - & - & constante & $\Delta \boldsymbol{e}_{i t-4,}$ constante \\
\hline \multirow[t]{2}{*}{ Teste de Sargan } & - & - & 9,1283 & 16,2492 \\
\hline & & & 0,1665 & 0,3657 \\
\hline \multirow{2}{*}{ Teste Correlação serial $1^{a}$ ordem } & - & - & 0,9009 & $-0,4911$ \\
\hline & & & 0,3676 & 0,6233 \\
\hline \multirow[t]{2}{*}{ Teste de correlação serial $2^{a}$ ordem } & - & - & $-2,0761$ & $-0,6184$ \\
\hline & & & 0,0379 & 0,5363 \\
\hline$\lambda$ & 0,002 & 0,042 & 0,026 & 0,014 \\
\hline$\alpha$ & 0,97 & 0,36 & 0,60 & 0,79 \\
\hline
\end{tabular}

Tabela 7 - Estimação Modelo de Convergência

Fonte: elaborado pelos autores.

***, ${ }^{* *},{ }^{*}$ representam significância a $1 \%, 5 \%$ e $10 \%$ respectivamente.

Estatística t entre parênteses, p-valor em negrito.

19 Conforme Islam (2003).

20 Reescrevendo de outra forma: $\beta_{1}=\gamma-1$. Neste trabalho foram reportados os valores do coeficiente $\beta_{1}$. 
Nas estimações, constatou-se a relação positiva que a poupança possui com o nível das emissões, assim como prevê o modelo de Solow verde. Além disso, a relação negativa da taxa de depreciação efetiva apontada no modelo teórico se manteve. E a convergência, apontada pelo sinal negativo do termo defasado das emissões, também se verificou. A taxa de convergência implícita $\lambda$ pode ser considerada uma taxa relativamente baixa, enquanto a fração da renda que remunera o capital $\alpha$ é mais elevada no caso de estimadores fixos e convergência absoluta. Nos demais casos, a estimativa de $\alpha$ é consistente com aquela normalmente encontrada na literatura (ao redor de $1 / 3$ ) ou com a estimativa referente a um conceito mais amplo de capital (ao redor de 2/3).

Com relação à estimação utilizando o método System-GMM, a validade das estimações está sujeita aos resultados dos testes de Sargan e do teste de correlação serial sobre o resíduo transformado. O teste de Sargan verifica se os instrumentos utilizados nas regressões são válidos. A rejeição da hipótese nula implica que as restrições de sobreidentificação do modelo não são válidas. Todos os testes apontaram para a não rejeição de $\mathrm{H}_{0}$, o que implica que os instrumentos são válidos. O outro conjunto de testes busca verificar se os resíduos transformados de $1^{\mathrm{a}}$ e $2^{\mathrm{a}}$ ordem apresentam correlação serial. A hipótese nula, neste caso é ausência de correlação serial. Com exceção do modelo de convergência absoluta, todos os demais testes apontaram para a não rejeição de $\mathrm{H}_{0}$.

De uma forma geral, as estimações através do System-GMM acompanharam os resultados do painel de Efeitos Fixos, ainda que de forma implícita, pois as magnitudes dos coeficientes foram diferentes. Conforme ressaltam Brock e Taylor (2010), o modelo de Solow verde é mais robusto do que a estimação de uma CAK tradicional. Tal fato, de certa forma, foi comprovado neste trabalho. Utilizando dois modelos diferentes na estimação da CAK, os resultados também foram diferentes, pelo menos pelo método FMOLS. Já na estimação do modelo de convergência, utilizando-se dois estimadores diferentes, os resultados foram muito próximos.

Comparando o modelo de convergência de Brock e Taylor (2010) com os resultados obtidos por meio da estimação da CAK, pode-se concluir que, apesar dos resultados apontarem para a convergência das emissões, não se pode afirmar que ocorre uma curva no formato 
de $\mathrm{U}$ invertido, uma vez que os pontos de inflexão próximos à realidade foram obtidos por meio de uma curva no formato de N. Este resultado não implica que o modelo de Solow Verde não é capaz de descrever a CAK, conforme apontam Brock e Taylor (2010), mas sim que a estimação econométrica da CAK pode realmente ser passível de falhas, como ressaltam Stern (2004) e Wagner (2008).

Sendo assim, constata-se que no período considerado as emissões de dióxido de carbono apresentaram uma taxa de crescimento equilibrado, o que representa uma taxa constante de crescimento rumo ao estado estacionário. Mas isso não implica que o nível de emissões de dióxido de carbono tenha sido baixo, mas apenas que o crescimento das emissões é dado por uma taxa constante.

\section{Conclusão}

Os resultados obtidos neste trabalho estão em conformidade com aqueles descritos em Brock e Taylor (2010), apontando para a convergência das emissões e, implicitamente, a existência de uma CAK. Porém, quando se utilizou a metodologia de estimação da CAK, foi apontada uma curva no formato $\mathrm{N}^{21}$ o que difere da curva no formato de $\mathrm{U}$ invertido, implícita no modelo proposto por Brock e Taylor (2010).

O modelo de convergência de Brock e Taylor (2010) possui duas limitações importantes. A primeira é considerar nulos os custos de abatimento do carbono. A outra limitação é que o modelo por si só não permite o cálculo empírico do ponto de inflexão. Embora os autores tenham obtido em sua análise do modelo teórico o instante em que ocorre o ponto de inflexão, bem como a renda per capita e as emissões associadas a esse ponto, sua estimação não foi implementada no artigo original. Enfim, mesmo que as emissões de dióxido de carbono tenham apresentado uma taxa de crescimento constante, é essencial o uso de políticas ambientais que criem os incentivos para redução do nível de emissão de poluentes, em especial pela adoção de tecnologias menos poluentes. Ratificando o que autores como

${ }^{21}$ Considerando o modelo que gerou estimativas para os pontos de inflexão cujos valores da renda per capita implicados estão mais próximos dos valores que a renda per capita assume na realidade para os países considerados.

Estud. Econ., São Paulo, vol.45, n.1, p. 97-126, jan.-mar. 2015 
Grossman e Krueger (1995) e Hilton e Levinson (1998) salientam, temos que o crescimento econômico por si só não é capaz de provocar necessariamente a redução das emissões a um nível de renda per capita factível. É preciso que haja uma ação conjunta de governos, países, indústrias e pessoas para que possamos ter um crescimento econômico associado a um ambiente mais limpo, obtendo dessa forma a sustentabilidade.

\section{Referências}

ARELLANO, M.; BOVER, O. Another look at the instrumental variable estimation of error components models. Journal of Econometrics, v. 68, n. 1, p. 29-51, 1995.

AUCI, S.; BECCHETTI, L. The instability of the adjusted and unadjusted Environmental Kuznets Curves. Ecological Economics, v. 60, p. 282-298, 2006.

BALTAGI, B. H. Econometric Analysis of Panel Data. 3. ed. Inglaterra: John Wiley \& Sons, 2005.

BANCO MUNDIAL. World Development Indicators. Estados Unidos, 2011.

BARRO, R. J.; SALA-i-MARTIN. Economic Growth-second edition. Cambridge, MA: MIT Press, 2004.

BAUMOL, W. J.; OATES, W. E. The theory of environmental policy - second edition. Cambridge: Cambridge University Press, 1988.

BLUNDELL, R.; BOND, S. Initial conditions and moment restrictions in dynamic panel data models. Journal of Econometrics, v. 87, p. 115-143, 1998.

BREITUNG, J.; PESARAM, M. H. Unit roots and cointegration in panels. Frankfurt: Deutsche Bundesbank, 2005.

BROCK, W. A.; TAYLOR, M. S. The green Solow model. Journal of Economic Growth, v. 15, p. 127-153, 2010.

CAMERON, A. C.; TRIVEDI, P. K. Microeconometrics: Methods and Applications. New York: Cambridge University Press, 2005.

CAMPBELL, J. Y.; MANKIW, N. G. Consumption, income, and interest rates: reinterpreting the time series evidence. NBER Macroeconomics Annual, v. 4, p. 185-216, 1989.

CARVALHO, T. S.; ALMEIDA, E. A hipótese da Curva de Kuznets Ambiental Global: uma perspectiva econométrico-espacial. Estudos Econômicos, v. 40, n. 3, p. 587-615, p. 1149-1159, 2010.

CHENG, S. Y.; WEI, J. S.; HOU, H. A cointegration analysis of purchasing power parity and country risk. International Journal of Business and Economics, v. 7, p. 199-211, 2008.

COLE, M. A.; ELLIOT, R. J. R.; AZAR, A. K. The determinants of trade in pollution intensive industries: North South evidence. University of Birmingham, 2001.

DASGUPTA, S.; LAPLANTE, B.; WANG, H.; WHEELER, D. Confronting the Environmental Kuznets Curve. Journal of Economic Perspectives, v. 16, p. 147-168, 2002.

DE BRUYN, S. M. Economic Growth and the Environment. Dordrecht: Kluwer Academic Publishers, 2000.

DINDA, S. A theoretical basis for the Environmental Kuznets Curve. Ecological Economics, v. 53, p. $403-413,2005$.

DINIZ, E. M. Crescimento, poluição e o Protocolo de Quioto: uma avaliação do caso brasileiro. São Paulo: Banco Santos / Universidade de Oxford, 2001. 
Lessons from the Kyoto protocol. Ambiente e Sociedade, v. 10, n. 1, p. 27-38, 2007.

FONSECA, L. N.; RIBEIRO, E. P. Preservação ambiental e crescimento econômico no brasil. In: Encontro de economia da Região Sul, VII. Rio Grande do Sul: [s.n.], 2005.

GROSSMAN, G. M.; KRUEGER, A. B. Environmental impacts of a North American free trade agreement. National Bureau of Economic Research, 1991.

Economic growth and the environment. Quarterly Journal of Economics, v. 110, p. 353-377, 1995.

HESTON, A.; SUMMERS, R.; BETTINA, A. Penn World Table Version 7.0. Center for International Comparisons of Production, Income and Prices at the University of Pennsylvania, Maio, 2011.

HILTON, F. G. H.; LEVINSON, A. Factoring the Environmental Kuznets Curve: evidence from automotive lead emissions. Journal of Environmental Economics and Management, v. 35, p. 126-141, 1998.

INTERNACIONAL ENERGY AGENCY. $\mathrm{CO}_{2}$ Emissions from Fuel Combustion. Paris: IEA, 2010.

ISLAM, N. Growth empirics: A panel data approach. The Quarterly Journal of Economics, v. 110, n. 4, p. $1127-1170,1995$.

What have we learnt from the convergence debate? Journal of Economic Surveys, v. 17, n. 3, p. 309-362, 2003.

LEVIN, A.; LIN, C. F.; CHU, C. S. J. Unit roots tests in panel data: asymptotic finite sample properties. Journal of Econometrics, v. 108, p. 1-24, 2002.

LIST, J. A. Have air pollutant emissions converged among U.S. regions? Evidence from unit root tests. Southern Economic Journal, v. 66, n. 1, p. 144-155, 1999.

MEADOWS, D. H. et al. The limits to growth. New York: Universe Books, 1972.

PANAYOTOU, T. Empirical tests and policy analysis of environmental degradation at different stages of economic development. Technology and Employment Programme, 1993.

PEDRONI, P. Critical values for cointegration tests in heterogeneous panels with multiple regressors. Oxford Bulletin of Economics and Statistics, v. 61, p. 653-670, 1999.

. Fully modified ols for heterogeneous cointegrated panels. Advances in Econometrics, v. 15, p. 93-130, 2000.

Panel Cointegration: Asymptotic and Finite Sample Properties of Pooled Time Series Tests with an Application to the PPP Hypothesis. Econometric Theory, v. 20, p. 597-625, 2004.

PERMAN, R.; MA, Y.; COMMON, M.; MADDISON, D.; McGILVRAY, J. Natural Resource and Environmental Economics $-4^{\text {th }}$ edition. Essex: Pearson, 2011.

ROMER, D. Advanced Macroeconometrics. 2. ed. Nova Iorque: McGraw-Hill, 2001.

SELDEN, T. M.; SONG, D. Environmental quality and development: is there a Kuznets Curve for air pollution emissions? Journal of Environmental Economics and Management, v. 27, n. 2, p. $147-162,1994$.

SHAFIK, N.; BANDYOPADHYAY, S. Economic growth and environmental quality: a time series and cross-country evidence. Journal of Environmental Economics and Management, v. 4, p. 1-24, 1992.

SOLOW, R. A contribution to the theory of economic growth. Quarterly Journal of Economics, v. 70, p. 65-94, 1956.

STERN, D. I. The rise and fall of the environmental Kuznets curve. World Development, v. 32, p. 1419-1439, 2004.

STOKEY, N. L. Are there limits to growth? International Economic Review, v. 39, n. 1, p. 1-31, 1998.

WAGNER, M. The carbon Kuznets Curve: a cloudy picture emitted by bad econometrics? Resource and Energy Economics, v. 30, p. 388-408, 2008.

WESTERLUND, J. Testing for error correction in panel data. Oxford Bulletin of Economics and Statistics, v. 69, p. 709-748, 2007.

Estud. Econ., São Paulo, vol.45, n.1, p. 97-126, jan.-mar. 2015 